\title{
MOTIVOS PARA RECOMPRA DE AÇÕES: UMA ANÁLISE COM AS EMPRESAS DA BM \&FBOVESPA E DA NYSE
}

Inajá Allane Santos Garcia ${ }^{2}$

Wenner Glaucio Lopes Lucena ${ }^{3}$

\begin{abstract}
Resumo: Este trabalho analisou os motivos para a recompra de ações realizadas pelas empresas listadas na BM\&FBovespa e na NYSE. Os motivos mais citados na literatura foram objetos de estudo desta pesquisa, são eles: (a) fluxo de caixa livre; (b) sinalização de que as ações estão subavaliadas; (c) distribuição de dividendos; e (d) interesse das empresas em ajustar a estrutura de capital por meio da alavancagem. Para alcance do objetivo deste estudo, cada motivo elencado para recompra de ações gerou uma hipótese de pesquisa. Quanto à amostra final da pesquisa, foi composta por 353 empresas não financeiras listadas na BM\&FBovespa e 3.400 listadas na NYSE. Destas, 74 e 1.739 empresas, listadas respectivamente na BM\&FBovespa e NYSE, realizaram recompra de ações em pelo menos um dos anos da amostra (2000 a 2014). Todos os dados utilizados foram coletados na base de dados da Thomson Reuters Eikon ${ }^{\mathrm{TM}}$ e organizados em um painel desbalanceado, uma vez que não foi possível verificar todos dados para todas as empresas em todos os anos da análise. Os resultados apontaram que, para a estimação composta pelas empresas da BM\&FBovespa, apenas o motivo do fluxo de caixa livre explica a recompra de ações, enquanto que, para a estimação composta pelas empresas da NYSE, os motivos determinantes para a recompra de ações foram o fluxo de caixa livre e a distribuição de dividendos. Conclui-se, então, que há diferenças entre os motivos para a recompra de ações efetuada pelas empresas que compõem a BM\&FBovespa e a NYSE. Isso pode se justificar pelo nível de desenvolvimento dos mercados nos quais essas empresas estão inseridas.
\end{abstract}

Palavras-chave: Recompra de ações; Motivos; BM\&FBovespa; NYSE.

\footnotetext{
1 Trabalho premiado como melhor trabalho na área de Mercados Financeiro, de Crédito e de Capitais no X Congresso Anpcont 2016 - Ribeirão Preto/SP.

2 e-mail: inajaallane@hotmail.com. Centro Universitário de João Pessoa - Unipê.

${ }^{3}$ e-mail: wdlucena@yahoo.com.br. Universidade Federal da Paraíba - UFPB.

- DOI: http://dx.doi.org/10.14392/asaa.2017100102

- Artigo submetido em: 27/07/2016. Revisões requeridas em: 20/01/2017. Aceito em: 06/02/2017
} 


\title{
REASONS FOR REPURCHASE OF SHARES: AN ANALYSIS WITH COMPANIES BM\&FBOVESPA AND NYSE
}

\begin{abstract}
This study analyzed the reasons for the repurchase of shares held by companies listed on the BM \& FBovespa and the NYSE. The reasons most often cited in the literature were objects of study of this research are: (a) free cash flow; (b) signaling that the shares are undervalued; (c) distribution of dividends; and (d) interest of companies to adjust the capital structure through leverage. To reach the objective of this study, each part listed reason for share repurchase generated a research hypothesis. As for the final survey sample was comprised of 353 non-financial companies listed on the BM \& FBovespa and 3,400 listed on the NYSE. Of these, 74 and 1,739 companies listed respectively on BM\&FBovespa and NYSE, conducted buybacks in at least one of the years of the sample (2000-2014). All data were collected in the database of Thomson Reuters Eikon ${ }^{\mathrm{TM}}$ and organized in an unbalanced panel, since it was not possible to verify all data for all companies in each year of the analysis. The results showed that for the estimation composed by companies of BM\&FBovespa, only the reason for the free cash flow explains the repurchase of shares, while for the estimation consisting of the companies of the NYSE, the decisive reasons for repurchases were free cash flow and dividend distribution. It follows, then, that there are differences between the reasons for the repurchase of shares made by the companies that make up the BM\&FBovespa and the NYSE. This can be justified by the market development level in which these companies operate.
\end{abstract}

Keywords: Repurchase of shares; Reasons; BM\&FBovespa; NYSE. 


\section{INTRODUÇÃO}

A primeira oferta de ações realizada por uma empresa em um mercado aberto é denominada de Initial Public Offering (IPO) ou Oferta Pública Inicial, em português. Isso significa que a organização está ofertando o seu capital e que vários investidores agora podem fazer parte da sua estrutura de propriedade.

Arikan e Capron (2010) afirmam que, nessa ocasião, a firma eleva seu capital com a venda parcial da propriedade em vez de emitir títulos de dívida. Ainda na percepção desses autores, os estudiosos de finanças consideram IPO como um evento de liquidez, enquanto os estudiosos da sociologia e da gestão visualizam essa oferta como um processo social, durante o qual a empresa forma novas relações com importantes parceiros, o que pode ter uma influência fundamental na sua estratégia e sobrevivência.

Uma vez que as ações da empresa estão disponíveis no mercado, qualquer investidor pode adquiri-las, inclusive a companhia que as lançou no mercado. A esse fenômeno pelo qual a própria companhia readquire suas ações, dá-se o nome de recompra de ações. Nesse tipo de transação a empresa utiliza os recursos disponíveis em caixa para recomprar suas próprias ações em circulação e as mantém em tesouraria, podendo revendê-las se a empresa necessitar de caixa no futuro (Berk \& DeMarzo, 2010).

Levando em consideração que as empresas ofertam suas ações no mercado como forma de captar recursos para investir em si mesma, objetivando o seu crescimento e melhores condições de competitividade, quais seriam os motivos que conduziriam essas empresas a realizar a recompra de ações de sua própria emissão? Como explica Dittmar (2000), tais motivos estão atrelados a alguns tipos de decisões empresariais, como, por exemplo, as decisões de investimento, política de distribuição de lucros, estrutura de capital, controle da organização e alavancagem.

Os estudiosos do mercado tendem a procurar uma explicação para justificar a recompra de ações, porém, não há um motivo único para isso (Grullon \& Ikenberry, 2000). Muitos podem ser os motivos que conduzem as empresas a recomprarem suas ações, dentre eles estão: (a) fluxo de caixa livre; (b) sinalização de que as ações estão subavaliadas; (c) distribuição de dividendos; e (d) interesse das empresas em ajustar a estrutura de capital por meio da alavancagem, que são os mais abordados pelos estudos de Vermaelen (1981), Nohel e Tarhan (1998), Stephens e Weisbach (1998), Dittmar (2000), Jagannathan, Stephens e Weisbach (2000), Grullon e Michaely (2002), Grullon e Michaely (2004), Chan, Ikenberry e Lee (2004), Park e Jung (2005), Eije e Megginson (2008), Jain, Shekhar e Torbey (2009), Liang (2012), Boudry, Kallberg e Liu (2013), Jiang, Kim, Lie, e Yang (2013) e Wang,Lin, Fung, e Chen (2013). Esses quatro motivos apresentados são objetos de estudo desta pesquisa, pois, de acordo com Ikenberry, Lakonishok e Vermaelen (2000) e Gabrielli e Saito (2004), são os principais motivos que explicam a recompra de ações.

Vale salientar que, dependendo do mercado no qual a empresa está inserida, os motivos para a decisão de recompra das empresas podem ser distintos, uma vez que,de acordo com Sarquis, Silva, Voese e Fonseca (2014), cada mercado possui características diferentes, como o grau de evolução do mercado de capitais, políticas internas governamentais, dentre outros fatores. Um exemplo disso é o mercado de capitais brasileiro e o norte-americano, nos quais estão inseridas as empresas listadas na Bolsa de Valores, Mercadorias e Futuros de São Paulo (BM\&FBovespa) e New York Stock Exchange (NYSE) respectivamente. A escolha dessas duas bolsas se deu em virtude de algumas diferenças marcantes entre os dois mercados nos quais atuam, como por exemplo a concentração acionária, liquidez e algumas regulamentações. O mercado brasileiro é conhecido pela forte concentração acionária, baixa liquidez e notável influência da legislação no funcionamento do mercado e a NYSE, na visão de Berk e 
DeMarzo (2010) recebe destaque por ser o mercado de ações mais conhecido dos Estados Unidos da América (EUA) e também é o maior do mundo, isso pelo fato de serem negociados diariamente bilhões de dólares em ações.

Diante disso, busca-se responder ao seguinte problema de pesquisa: Quais são os motivos para recompra de ações efetuadas por empresas listadas na BM\&FBovespa e na NYSE?Para responder essa problemática, tem-se como objetivo analisar quais são os motivos determinantes para recompra de ações efetuadas por empresas listadas na BM\&FBovespa e na NYSE.

Sobre a recompra de ações, Boudry et al. (2013) destacam que tem sido amplamente estudada em pesquisas financeiras nas últimas quatro décadas, além de serem cada vez mais significativas em mercados financeiros globais, como, por exemplo, no ano de 1999, quando as empresas dos Estados Unidos da América (EUA), pela primeira vez na história, apresentaram o volume do montante de dólares de recompra superior ao montante de dividendos a pagar.

Este estudo torna-se relevante, porque procura evidenciar as motivações determinantes para a recompra de ações de empresas em dois cenários diferentes, o da BM\&FBovespa e o da NYSE, apresentando aos stakeholders maiores informações acerca da decisão de recompra efetuada pelas empresas. A partir dos resultados desta pesquisa, espera-se que os investidores e acionistas possam refletir sobre as estratégias e informações que estão por trás da decisão de recompra de ações.

\section{FUNDAMENTOS TEÓRICOS}

\subsection{MOTIVOS PARA RECOMPRA DE AÇÕES E ELABORAÇÃO DAS HIPÓTESES DA PESQUISA}

A literatura apresenta alguns motivos que conduzem as empresas a recomprarem suas próprias ações, sendo os mais discutidos: (a) fluxo de caixa livre; (b) sinalização de que as ações estão subavaliadas; (c) distribuição de dividendos; e (d) interesse das empresas em ajustar a estrutura de capital por meio da alavancagem (Gabrielli \& Saito, 2004, Nascimento, Galdi \& Nossa, 2011).

\subsubsection{Fluxo de Caixa Livre}

Essa motivação para a recompra de ações surge a partir da teoria do fluxo de caixa livre (FLC), desenvolvida por Jensen (1986). Sob a luz dessa teoria, a existência de FLC na organização dá origem ao conflito de agência entre o principal e o agente (Lakonishok \& Vermaelen, 1990), conflito esse relacionado à política de distribuição da empresa, em que o pagamento de dividendos realizado aos acionistas cria grandes conflitos, uma vez que reduzem os recursos sob o controle do gestor (Jensen,1986).

Como afirmam Park e Jung (2005), a hipótese do fluxo de caixa livre, desenvolvida a partir da teoria do fluxo de caixa livre, utilizada para explicar a recompra de ações, enfoca o problema de agência entre gestores e acionistas sobre a distribuição dos fluxos de caixa livres, afirmando que o gestor com substancial FCL irá investir em projetos com valor presente líquido (VPL) negativo, que resultam em ineficiências organizacionais, em vez de distribuir esse excesso aos acionistas.

Quando se observa algum problema de agência entre os gestores e o acionista, surgem os custos de agência, que existem devido às ferramentas que o principal (acionista) utiliza a fim de controlar as ações do agente (gestor). Nesse sentido, uma empresa que possui altos custos de agência implica em elevados fluxos de caixa livre e baixas oportunidades de investimento (Wang et al., 2013). Nohel e 
Tarhan (1998) complementam que as empresas com excesso de fluxo de caixa e baixas oportunidades de investimento irão enfrentar um custo de agência considerável, se o excesso de caixa não for distribuído aos acionistas. Ainda na visão desses autores, sem essa distribuição aos acionistas, os gestores possuem incentivos a investir o excedente de caixa em gratificações e outros projetos de VPL negativo.

Dittmar (2000) afirma que uma das formas de minimizar o conflito de agência é reduzir o fluxo de caixa em excesso, e, para reduzir esse caixa, Grullon e Michaely (2004) sugerem o aumento no nível de distribuição da empresa. Howe, He e Kao (1992) concordam e acrescentam que isso contribui para evitar o desperdício com investimentos de VPL negativo.

Jensen (1986) enfatiza que a redução do fluxo de caixa pode ocorrer por meio da distribuição de dividendos e da recompra de ações, o que evitaria desperdiçar esses recursos em projetos de baixo retorno. As recompras de ações permitem que a empresa distribua o excesso de fluxo de caixa, eliminando, assim, o incentivo para o desperdício de investimento, aumentando o valor da empresa (Nohel \& Tarhan, 1998), uma vez que os gestores não mais utilizarão o caixa disponível em investimentos de VPLs negativos. Em outras palavras, Park e Jung (2005) explicam que a recompra de ações evita decisões de investimentos em projetos não rentáveis, o que resulta em significativos efeitos de valorização na empresa.

Bessler, Seim e Zimmermann (2015) esclarecem que os pagamentos realizados aos acionistas na forma de recompra de ações indicam que a organização tem menos oportunidades de crescimento, requer menos recursos para investimentos e está se movendo em direção a uma fase mais madura do seu ciclo devida. Na concepção de Boudry et al. (2013), em seu ciclo de vida normal, as empresas tendem a atingir a maturidade, porém, as condições de mercados evoluem e as oportunidades de investimentos podem diminuir e/ou aumentar seus fluxos de caixa.

Devido a isso, algumas empresas, com o objetivo de maximizar o valor do acionista, optam por comprar de volta suas ações, em vez de investir em projetos de VPL negativo (Boudry et al., 2013). Normalmente, a empresa, quando está em fase de crescimento, tem muitos projetos com VPL disponíveis e elevadas despesas de capital, porém, quando o crescimento da empresa fica mais baixo, as despesas de capital diminuem e a empresa gera grande quantidade de fluxos de caixa livre (Grullon \& Michaely, 2004). Com base no exposto, tem-se a seguinte hipótese de pesquisa:

- Hipótese 1: o FCL explica a recompra de ações efetuada pelas organizações.

Essa hipótese prevê que as empresas tendem a comprar de volta suas ações quando possuem elevados FCLs, podendo reduzir os custos de agência, ou seja, a recompra de ações permite que as empresas evitem investir em projetos de VPL negativo e também sinalizam a redução dos custos de agência para o mercado (Wang et al., 2013). A exemplo de Dittmar (2000), espera-se que as empresas com elevados excesso de caixa ou de fluxo de caixa recomprem ações.

\subsubsection{Sinalização de que as Ações estão Subavaliadas}

Na opinião de Grullon e Ikenberry (2000), a explicação mais discutida na literatura para justificar a recompra de ações é que os gerentes corporativos usam a recompra de ações como um sinal de seu otimismo sobre as perspectivas da empresa para o mercado.

Desenvolvida por Spence (1973), a teoria da sinalização explica o comportamento do mercado de trabalho, buscando reduzir a assimetria informacional existente entre o principal e o agente. É neste sentido que Grullon e Michaely (2004) destacam a existência de estudos sobre o potencial das recompras de servirem como mecanismo de sinalização para corrigir a subavaliação das ações das 
empresas, a exemplo dos estudos de Vermaelen (1981), Nohel e Tarhan (1998), Stephens e Weisbach (1998), Dittmar (2000), Chan et al.(2004), Grullon e Michaely (2004), Park e Jung (2005), Liang (2012) e Wang et al. (2013). Com base nesse argumento de assimetria de informações entre o mercado e os gestores de uma empresa, subavaliação é a razão mais importante para as empresas recomprarem suas ações (Wang et al., 2013).

Stephens e Weisbach (1998) acreditam que as empresas compram de volta o seu próprio capital, ou seja, realizam recompra de ações, quando seus gestores têm informações privadas sobre a subavaliação das ações da empresa. Os gestores possuem conhecimento superior sobre o verdadeiro valor de sua empresa e, por isso, recompram suas ações quando o mercado a desvaloriza (Boudry et al., 2013).

Dann (1981), Vermaelen (1981), Lakonishok e Vermaelen (1990),Comment e Jarrell (1991), Ikenberry et al. (2000) e Lie (2005)concordam com o fato de que a recompra pode ser reconhecida como uma estratégia de investimento, que sinaliza positivamente ao mercado de que as ações da empresa estão subavalidadas. Diante do exposto, formulou-se a seguinte hipótese:

- Hipótese 2: a sinalização de que as ações das empresas estão subavaliadas no mercado explica a recompra de ações efetuada pela firma.

Baseando-se na premissa de que os gestores estão mais bem informados do que o mercado sobre o verdadeiro valor da firma, essa hipótese considera que as empresas que recompram ações são caracterizadas por um elevado grau de assimetria de informação (Dittmar, 2000). Segundo Vermaelen (1981), assimetria de informação é, talvez, mais proeminente nas pequenas empresas, porque estas são menos cobertas por analistas financeiros.

\subsubsection{Distribuição de Dividendos}

Desde o momento do IPO, a organização enfrenta desafios consideráveis e incertezas relacionadas às condições do negócio, como as mudanças tecnológicas, condições de financiamento e concorrência no mercado, as quais se estendem durante a fase pós-IPO, a qual oferece um ambiente propício para avaliar a escolha de forma de pagamento aos investidores (Jain et al., 2009).

Nesse sentido, Dittmar (2000) enfatiza que tanto a recompra de ações como a distribuição de dividendos são maneiras de distribuir o excesso de capital para os acionistas (Dittmar, 2000). Isso porque a organização pode distribuir os dividendos, como ocorre normalmente após a contabilização do resultado da empresa, e/ou pode recomprar as ações da companhia, mantê-las em tesouraria e distribuir como forma de pagamento aos acionistas. Dittmar (2000) ainda enfatiza que a recompra de ações tem preferência sobre a distribuição de dividendos por dois motivos: (a) na recompra pelo mercado aberto não há o comprometimento da operação ser efetivada, logo, a empresa pode desistir da recompra, além de não haver o compromisso de que a recompra ocorra em base regular, como é o caso da distribuição de dividendos; e (b) com a recompra, a empresa tem uma vantagem em relação aos impostos, uma vez que a tributação dos ganhos de capital é realizada por taxas menores que a tributação dos dividendos.

Sendo assim, é possível compreender que a recompra de ações realizada pelo open market não é um compromisso firme de que ocorra apenas a compra das ações que foram previstas. Quanto ao segundo motivo, vale ressaltar que, em vários países, como, por exemplo, os EUA, a distribuição de dividendos possui uma tributação maior do que a da recompra de ações, porém, no Brasil, isso não se aplica, uma vez que os ganhos de capital são tributados, mas os dividendos são isentos, por isso a preferência por dividendos (Nascimento et al., 2011). 
Sendo assim, a distribuição (payout) de dividendos e a recompra de ações realizadas pelas empresas estariam relacionadas, embora essa relação possa variar de acordo com a legislação que rege cada país no qual a empresa negocia.De acordo com o exposto, formulou-se a seguinte hipótese:

- Hipótese 3: a distribuição de dividendos explica a recompra de ações efetuada pela empresa.

Com relação a essa hipótese, Dittmar (2000) afirma que, se as empresas recompram ações como forma de substituir os dividendos, a fim de reduzir a carga fiscal, logo, as empresas que pagam dividendos baixos ou as que não pagam dividendos são mais propensas a recomprar ações.

\subsubsection{Interesse das Empresas em Ajustar a Estrutura de Capital por meio da Alavan- cagem}

Inicialmente, é relevante dizer a que se refere a estrutura de capital, ou seja, a forma como as empresas utilizam o capital próprio e o capital de terceiros para financiar seus ativos.Nesse sentido, a estrutura de capital vem sendo discutida por meio de duas teorias: a tradicionalista, introduzida por Durand (1952), e a teoria de Modigliani e Miller (1958).

A teoria convencional ou tradicionalista defendida por Durand (1952) parte do pressuposto de que a estrutura de capital da empresa influencia no valor de mercado. Dessa forma, a empresa deveria atingir um ponto de estrutura de capital ótima, a qual conduziria a maximização do valor da empresa. A estrutura de capital ótima se atinge quando a empresa consegue, de certa forma, equilibrar o seu custo total de capital, sem incorrer em risco de falência, o que seria causado pelo aumento do custo de capital de terceiros acima do aceitável e provocaria uma diminuição do valor da empresa. Assim, assume-se que existe um índice de alavancagem alvo ou ótimo a ser atingido pela empresa.

Diferentemente da teoria tradicionalista, a de Modigliani e Miller (1958), que, em um ambiente sem impostos, inicialmente defende que a estrutura de capital não tem qualquer influência sobre o valor de mercado, ou seja, a forma como os financiamentos da empresa estão distribuídos é irrelevante para o valor da empresa. Isso significa que não importa se determinado projeto é financiado com recursos de terceiros ou próprios, o retorno sobre o ativo continuará constante (Kayo \& Famá, 1997).

Posteriormente, considerando um ambiente com a presença de impostos, Modigliani e Miller (1963) demonstraram que, quando há aumento do risco com maior participação de terceiros na estrutura de capital, os acionistas requerem maior retorno sobre o capital investido, enquanto que o custo total do capital diminui com a dedução dos juros no cálculo do Imposto de Renda, proporcionando um aumento no valor da empresa. A respeito disso, Kayo e Famá (1997) enfatizam que, independentemente do enfoque dado ao estudo da estrutura de capital, o certo é que nenhum deles chega a ser conclusivo.

Neste estudo, considera-se a teoria apresentada por Durand (1952). Se a empresa acha que está pouco endividada e possui mais capital próprio do que precisa, a recompra de ações pode permitir a reorganização do balanço, de forma que o capital próprio e capital de terceiros estejam distribuídos de forma mais adequada (Gabrielli \& Saito, 2004). Isso acontece porque, quando uma empresa recompra ações, as ações são reduzidas e, portanto, o índice de alavancagem aumenta (Park \& Jung, 2005). A respeito disso, Broudry, Kallberg e Liu (2013) afirmam que a recompra de ações aumenta a alavancagem, assim, empresas com alto índice de alavancagem são menos propensas a recomprar ações, já que a alta alavancagem vai aumentar os custos de falência esperados (Boudry et al., 2013).

Hipótese 4: o interesse da empresa em ajustar a sua estrutura de capital por meio da alavancagem explica a recompra de ações por ela efetuada. 
Essa hipótese, denominada de hipótese da alavancagem, prevê que as empresas recompram ações quando o seu índice de alavancagem é inferior ao seu índice de alavancagem alvo (Dittmar, 2000).

\section{METODOLOGIA}

\subsection{UNIVERSO, AMOSTRA E COLETA DE DADOS}

O universo desta pesquisa compreende todas as empresas listadas na BM\&FBovespa e na NYSE. As unidades de análise são as companhias que realizaram recompra de ações no período de 2000 a 2014.

A escolha do ano de 2000 ocorreu em virtude do surgimento das Instruções da Comissão de Valores Mobiliários (CVM) n 299/1999 e n³45/2000, promovendo alterações nas operações de recompra de ações realizadas pelas empresas listadas na BM\&FBovespa (CVM, 2015).

Tanto a identificação das empresas que recompraram ações quanto as informações financeiras utilizadas nesta pesquisa foram coletadas junto à base de dados Thomson Reuters Eikon ${ }^{\text {TM}}$. Inicialmente, realizou-se a verificação das companhias que recompraram ações no período de 2000 a 2014, a partir das rubricas: (a) repurchase/ retirement of common; (b) repurchase/ retirement of preferred; (c) repurchase/ retirement of common/ preferred, que fazem parte da gama de itens de pesquisa da base de dados utilizada. Essas rubricas informavam o montante de recursos anuais utilizados nas operações de recompras de ações ordinárias, preferenciais e ordinárias/preferenciais, respectivamente. Em virtude disso, para a estimação do modelo, o montante de recursos de cada ano se substituiu por 1 (um), identificando as empresas que recompraram ações naquele ano, e para as empresas que não realizaram operações de recompra de ações atribuiu-se o valor 0 (zero).

É importante ressaltar que a identificação das empresas que recompraram ações fez-se por meio da coleta de dados junto à Thomson Reuters Eikon ${ }^{\text {TM }}$, independentemente do método de recompra utilizado na transação, a exemplo de Dittmar (2000), que também não segregou as empresas que recompraram ações por tipo de método utilizado, seja ele tender offer (oferta pública de aquisição), open market (mercado aberto) ou private purchase (compra privada).

A amostra inicial foi composta por 4.415 empresas, sendo 380 que compõem a BM\&FBovespa e4. 035que compõem a NYSE. Dentre estas, 27 empresas classificadas no setor financeiro da BM\&FBovespa e 635 empresas da NYSE,foram excluídas da amostra, uma vez que possuem particularidades quanto à sua estrutura de capital, o que poderia comprometer os resultados deste estudo. Restaram, assim, 353 e 3.400 empresas não financeiras listadas na BM\&FBovespa e na NYSE, respectivamente, das quais 74 e 1.739 empresas listadas respectivamente na BM\&FBovespa e NYSE, realizaram recompra de ações em pelo menos um dos anos da amostra (2000 a 2014).

A seguir, a Tabela 1 revela a quantidade de empresas que recompraram e que não recompraram ações nos anos de 2000 a 2014. Ressalta-se que uma empresa pode efetuar recompra de ações em mais de um período, assim, é possível que a mesma empresa recompre ações em todos os anos do período analisado. 
Tabela 1: Quantidade de empresas não financeiras listadas na BM\&FBovespa e NYSE que recompraram e não recompraram açoes nos anos de 2000 a 2014

\begin{tabular}{|c|c|c|c|c|c|c|}
\hline Anos & \multicolumn{3}{|c|}{ Quantidade de empresas listadas na BM\&FBovespa } & \multicolumn{3}{|c|}{ Quantidade de empresas listadas na NYSE } \\
\hline 2000 & 3 & 350 & 353 & 544 & 2.856 & 3.400 \\
\hline 2001 & 3 & 350 & 353 & 582 & 2.818 & 3.400 \\
\hline 2002 & 5 & 348 & 353 & 555 & 2.845 & 3.400 \\
\hline 2004 & 5 & 348 & 353 & 580 & 2.820 & 3.400 \\
\hline 2005 & 10 & 343 & 353 & 690 & 2.710 & 3.400 \\
\hline 2006 & 10 & 343 & 353 & 814 & 2.586 & 3.400 \\
\hline 2007 & 17 & 336 & 353 & 907 & 2.493 & 3.400 \\
\hline 2011 & 32 & 321 & 353 & 999 & 2.401 & 3.400 \\
\hline 2012 & 25 & 328 & 353 & 1.099 & 2.301 & 3.400 \\
\hline 2013 & 21 & 332 & 353 & 1.082 & 2.318 & 3.400 \\
\hline 2014 & 35 & 318 & 353 & 1.138 & 2.262 & 3.400 \\
\hline Total & 241 & 5.054 & - & 12.224 & 38.776 & \\
\hline
\end{tabular}

Essa diferença entre a quantidade de empresas que recompraram ações nas duas bolsas de valores pode ser um reflexo do desenvolvimento do mercado nos quais as bolsas estão inseridas: o mercado brasileiro e norte-americano, sendo este mais desenvolvido e com históricos de operações financeiras mais elevadas, e aquele considerado um mercado em crescimento. A respeito disso, Gabrielli e Saito (2003) enfatizam que a forte concentração acionária e a baixa liquidez do mercado brasileiro podem justificar o baixo volume de recompra nesse mercado.

\subsection{ESPECIFICAÇÃO DO MODELO EMPÍRICO}

Como forma de verificar se os 4 motivos apresentado na literatura explicam a ocorrência da recompra de ações, este estudo utilizou um modelo de regressão, a fim de comparar as diferenças e/ou semeIhanças entre os dois mercados. Ressalta-se que as empresas listadas na BM\&FBovespa e as listadas na NYSE foram estimadas separadamente, em virtude de as normas de contabilidade adotadas por ambos os grupos serem diferentes, pois este adota os United States Generally Accepted Accounting Principles (US GAAP) e aqueles as International Financial Reporting Standards (IFRS).

O método estatístico desenvolvido foi o modelo Logit, ou Regressão Logística, o qual possui a variável dependente sob forma binária. Quanto ao formato da equação da Regressão Logística aplicadas a este estudo, tem-se:

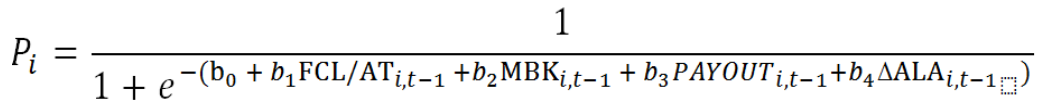

Em que:

$\mathrm{P}_{\mathrm{i}}=$ variável dependente binária, a qual apresenta valor igual a 1 (um) para as empresas que recompraram ações naquele ano, e valor igual a 0 (zero) para as empresas que não realizaram operações de recompra de ações; $\mathrm{e}=$ número irracional conhecido como Constante de Napier; $\mathrm{b}_{0}=$ constante; $\mathrm{b}_{1} \mathrm{a} \mathrm{b}_{4}=$ coeficientes estimados; $\mathrm{FCL}_{\mathrm{AT}} \mathrm{i}_{\mathrm{t}-\mathrm{1}}=$ representa o fluxo de caixa livre da empresa no ano anterior à recompra de ações; $\mathrm{MTB}_{\mathrm{i},-1}=$ representa o índice market-to-book das empresas no ano anterior à recompra 
de ações; PAYOUT $_{\mathrm{i}, \mathrm{t}-1}=$ representa o índice de pagamento de dividendos efetuado pelas empresas no ano anterior à recompra de ações; $\triangle \mathrm{ALA}_{\mathrm{i}, \mathrm{t}-1}=$ representa a diferença entre o índice de alavancagem da empresa e o índice de alavancagem alvo no ano anterior à recompra de ações.

É necessário enfatizar que, como o objetivo do trabalho é prever a decisão de recompra de ações feita pelas empresas, é necessária a verificação das variáveis explicativas no período anterior à recompra de ações.

Considerando que a estimação do modelo Logit será feita com dados em painel e que não há informações de todas as empresas durante todo o período analisado (2000 a 2014), utilizaram-se os dados organizados em um painel desbalanceado, não sendo possível obter o mesmo número de observações em cada ano.

Ainda sobre o método estatístico adotado, é relevante lembrar que a Regressão Logística é uma técnica utilizada quando a variável dependente é de natureza binária e, de acordo com Corrar, Paulo e Dias (2007), utilizando essa técnica, o pesquisador contorna algumas restrições observadas em outros modelos multivariados, como a homogeneidade de variância e a normalidade na distribuição dos erros. Porém, é necessário verificar se existe multicolinearidade entre as variáveis independentes do modelo, pois, de acordo com Brooks (2008), a existência de multicolinearidade pode gerar coeficientes distorcidos. Para isso, realizou-se o teste Variance Inflation Factor (VIF) na estimação do modelo.

\subsection{DEFINIÇÃO DAS VARIÁVEIS EXPLICATIVAS}

3.3.1 Hipótese do fluxo de caixa livre

Como fundamentado no referencial teórico, as empresas tendem a recomprar suas próprias ações quando possuem elevados $\mathrm{FCL}$, porque o fluxo de caixa em excesso pode acarretar conflitos de agência sobre a forma de utilização desse excesso. Neste sentido, Dittmar (2000) afirma que uma das formas de minimizar o conflito de agência entre o principal e o agente é reduzir o fluxo de caixa em excesso.

Para analisar a hipótese do fluxo de caixa livre, a exemplo de Wang et al. (2013) e Park e Jung (2005), utilizou-se o FCL da empresa. No caso deste estudo, retirou-se o valor do FCL diretamente da base de dados da Thomson Reuters Eikon ${ }^{\mathrm{TM}}$, que calcula tal variável como segue:

$$
F C L_{i, t-1}=\frac{F C_{i, t-1}-I N V E S T_{i, t-1}-D I V_{i, t-1}}{A T_{i, t-1}}
$$

Em que:

$\mathrm{FCL}_{\mathrm{i}, \mathrm{t}-1}=$ fluxo de caixa livre da empresa no ano anterior à recompra; $\mathrm{FC}_{\mathrm{i}, \mathrm{t}-1}=$ fluxo de caixa da empresa no ano anterior à recompra; INVEST $_{i, t-1}=$ dispêndio de capital utilizado para financiar os ativos da empresa no ano anterior à recompra; $\operatorname{DIV}_{i, t-1}=$ montante de dinheiro utilizado para pagamento dos dividendos totais anuais da empresa no ano anterior à recompra; $\mathrm{AT}_{\mathrm{i}, \mathrm{t}-\mathrm{i}}=$ ativo total da empresa no ano anterior à recompra.

Ressalta-se que, pelo fato de o FCL ser uma variável contábil, optou-se por ponderá-la pelo ativo total (AT) da empresa, eliminando o efeito do tamanho da firma.

\subsubsection{Hipótese de sinalização de subavaliação das ações}

Como exposto pela literatura deste trabalho, o fato de as empresas estarem subavaliadas pelo mercado demonstra uma motivação para as companhias readquirirem as próprias ações (Vermaelen, 1981, 
Stephens \& Weisbach, 1998, Ikenberry et al, 2000). Essa hipótese prevê que as empresas recompram ações quando o preço das ações é menor do que o seu valor verdadeiro (Dittmar, 2000).

Inicialmente, é necessário esclarecer que, naturalmente, é impossível determinar com certeza se uma empresa está subavaliada (Dittmar, 2000), mas a análise de algumas variáveis auxilia nessa missão. Assim como as pesquisas de Nohel e Tarhan (1998), Dittmar (2000), Jangannathan, Stephens e Weisbach (2000), Liang (2012), Lie (2005), Bessler et al. (2014), utiliza-se o market-to-book (MTB) para mensurar a subavaliação da empresa, o qual é calculado da seguinte maneira:

$$
M T B_{\mathrm{i}, \mathrm{t}-1}=\frac{\mathrm{VM}_{\mathrm{i}, \mathrm{t}-1}}{\mathrm{VC}_{\mathrm{i}, \mathrm{t}-1}}
$$

: Em que:

$\mathrm{MTB}_{\mathrm{i},-1}=$ índice market-to-book da empresa no ano anterior à recompra; $\mathrm{VM}_{\mathrm{i},-1}=$ valor de mercado da empresa no ano anterior à recompra; $\mathrm{VC}_{\mathrm{i},-1}=$ valor contábil da empresa no ano anterior à recompra.

As empresas com baixos índices de market-to-book são mais propensas a recomprarem ações (Dittmar, 2000, Wang et al, 2013), por causa do argumento da subavaliação das ações.

\subsubsection{Hipótese dos dividendos}

A distribuição de dividendos pode explicar a recompra de ações, porque tanto os dividendos como as ações adquiridas pelas empresas podem servir para pagamento aos acionistas. Dittmar (2000) afirma que, se as empresas recompram ações como forma de substituir os dividendos, para reduzir a carga fiscal, logo, as empresas que pagam dividendos baixos ou as que não pagam dividendos são mais propensas a recomprarem ações.

Com a intenção de verificar se a distribuição de dividendos explica a decisão de recompra de ações efetuada pela empresa, esta pesquisa testa a hipótese dos dividendos por meio da seguinte fórmula:

Em que:

$$
\text { PAYOUT }_{\mathrm{i}, \mathrm{t}-1}=\frac{\mathrm{DIV}_{\mathrm{i}, \mathrm{t}-1}}{\mathrm{LL}_{\mathrm{i}, \mathrm{t}-1}}
$$

PAYOUT $_{i, t-1}=$ índice de distribuição de dividendos da empresa no ano anterior à recompra; DIV i,t$1=$ montante de dinheiro utilizado para pagamento dos dividendos totais anuais da empresa no ano anterior à recompra; $\mathrm{LL}_{\mathrm{i}, \mathrm{t}-\mathrm{1}}=$ lucro líquido da empresa no ano anterior à recompra.

Essa variável é a mesma utilizada por Dittmar (2000), a qual analisou se as empresas que recompram pagam dividendos mais baixos.

\subsubsection{Hipótese de alavancagem}

A fim de verificar se o índice de alavancagem explica a recompra de ações da empresa, é preciso verificar o seu índice de alavancagem e compará-lo com o índice de alavancagem ótimo, o qual, para fins desse estudo, é representado pelo índice de alavancagem alvo (medido pela média dos indicadores das empresas pertencentes ao mesmo setor em determinado ano).

De acordo com Dittmar (2000), as empresas recompram ações quando o seu índice de alavancagem é inferior ao seu índice de alavancagem alvo. Para verificar essa afirmação, calcularam-se o índice de alavancagem da empresa e o índice de alavancagem alvo da seguinte maneira:

$$
\text { ALA DA EMPRESA }_{\mathrm{i}, \mathrm{t}-1}=\frac{P T_{\mathrm{i}, \mathrm{t}-1}-C X_{\mathrm{i}, \mathrm{t}-1}}{A T_{\mathrm{i}, \mathrm{t}-1}}
$$


Em que:

$\mathrm{ALA} \mathrm{DA} \mathrm{EMPRESA}_{\mathrm{i}, \mathrm{t}-1}=$ índice de alavancagem da empresa no ano anterior à recompra; $\mathrm{PT}_{\mathrm{i}, \mathrm{t}-\mathrm{f}}=$ valor do passivo total da empresa no ano anterior à recompra; $\mathrm{CX}_{\mathrm{i}, \mathrm{t}-\mathrm{t}}=$ montante de caixa e equivalentes de caixa disponíveis na empresa no ano anterior à recompra de ações; AT= valor do ativo total da empresa no ano anterior à recompra.

$$
\text { ALA ALVO }_{i, t-1}=\left(\frac{\mathrm{PT}_{\mathrm{i}, \mathrm{t}-1}-\mathrm{CX}}{\mathrm{AT} \mathrm{T}_{\mathrm{i}, \mathrm{t}-\mathrm{t}-1}}\right) \text { médio em cada ano }
$$

Em que:

$A L A A_{i, t-1}=$ índice de alavancagem alvo das empresas de um mesmo setor no ano anterior à recompra; $\mathrm{PT}_{\mathrm{i}, \mathrm{t}-1}=$ passivo total médio das empresas de um mesmo setor no ano anterior à recompra; $\mathrm{CX}_{\mathrm{i}, \mathrm{t}-1}=$ montante de caixa e equivalentes de caixa disponíveis médios das empresas de um mesmo setor no ano anterior à recompra; $\mathrm{AT}_{\mathrm{i}, \mathrm{t}-1}=$ valor do ativo total médio das empresas de um mesmo setor no ano anterior à recompra.

Ressalta-se que a variável utilizada no modelo econométrico desta pesquisa é calculada por meio da seguinte fórmula:

$$
\triangle \mathrm{ALA}_{\mathrm{i}, \mathrm{t}-1}=\mathrm{ALA} \mathrm{DA} \mathrm{EMPRESA}_{\mathrm{i}, \mathrm{t}-1}-\mathrm{ALAALV0}_{\mathrm{i}, \mathrm{t}-1}
$$

Em que:

$\triangle \mathrm{ALA}_{\mathrm{i}, \mathrm{t}-1}=$ diferença entre o índice de alavancagem da empresa e o índice de alavancagem alvo; ALA DA EMPRESA $_{\mathrm{i}, \mathrm{t}-1}=$ índice de alavancagem da empresa no ano anterior à recompra; $\mathrm{ALA} \mathrm{ALVO}_{\mathrm{i}, \mathrm{t}-1}=$ índice de alavancagem alvo das empresas de um mesmo setor no ano anterior à recompra.

Dessa forma, se há variação positiva entre o ALA DA EMPRESA e o ALA ALVO, indica que a empresa está como seu índice de alavancagem maior que a alavancagem ótima (representada pela alavancagem do setor no qual a firma está inserida), e provavelmente não irá recomprar ações, enquanto que, se o resultado dessa diferença for negativo, indica que a alavancagem está abaixo da alavancagem alvo, sendo, portanto, um incentivo para as empresas recomprarem ações.

Dittmar (2000) esclarece que se a hipótese de alavancagem afeta significativamente a decisão de uma firma de recomprar ações, então a alavancagem será menor para empresas que recompram ações (repurchasing) do que para as empresas que não recompram ações (nonrepurchasing), e o coeficiente sobre essa variável será negativo (Dittmar, 2000).

\section{ANÁLISE DOS RESULTADOS}

\subsection{ESTIMAÇÃO DO MODELO LOGIT PARA AS EMPRESAS LISTADAS NA BM\&FBOVESPA}

Sobre as observações inseridas na estimação do modelo, das 5.295 observações existentes, incluíram-se apenas 2.238, distribuídas entre o período de 2000 a 2014, uma vez que não foi possível a obtenção de todos os dados, pois não estavam disponíveis na base de dados da Thomson Reuters Eikon ${ }^{\mathrm{TM}}$.

Das 2.238 observações, 218 correspondem às empresas que recompraram ações, as quais representam cerca de $9,74 \%$ da amostra, enquanto que 2.020 correspondem às organizações que não efetuaram 
recompra. Esses dados reforçam que a estimação composta pelas empresas listadas na BM\&FBovespa é formado principalmente de informações das organizações que não recompraram ações, demonstrando que, no mercado no qual essas empresas estão inseridas, este tipo de operação não é muito comum.

É necessário enfatizar que realizou-se o teste de multicolinearidade, Variance Inflation Factor (VIF), o qual apontou que não há correlação significante entre as variáveis, uma vez que o maior VIF foi 2,704, apresentado pela variável FCL/AT.

Na Tabela 2 estão contidos os resultados da Regressão Logística formada pelas quatro variáveis independentes apresentadas na seção anterior. É relevante lembrar que as variáveis FCL/AT foi incluída no modelo a fim de avaliar se o FCL é um motivo determinante para recompra de ações, e o MTB representa o motivo de sinalização de subavaliação das ações. Quanto ao PAYOUT, é incluído para que se possa averiguar se a distribuição de dividendos influencia a recompra de ações, e a variável $\triangle A L A a-$ valia se o interesse da empresa em ajustar sua estrutura de capital por meio da alavancagem é um dos determinantes para a recompra de ações.

Os resultados sugerem que, das quatro variáveis, apenas uma influencia significativamente o evento de recompra de ações das empresas, a saber: FCL/AT. Pode-se perceber essa significância das variáveis pelo valor expresso na coluna Sig, como também pelo teste Wald, que verifica se cada parâmetro estimado é significativamente diferente de zero. Portanto, pode-se aproveitar no modelo apenas a variável FCL/ AT, uma vez que não apresenta coeficiente nulo, contribuindo para a explicação da recompra de ações.

Tabela 2: Resultados da estimação do modelo Logit para as empresas listadas na BM\&FBovespa, de 2000 a 2014

\begin{tabular}{|c|c|c|c|c|c|}
\hline Variáveis & $\beta$ & Erro-padrão & Wald & Sig & $\operatorname{Exp}(\beta)$ \\
\hline FCL/AT i,t-1 & 1,739 & 0,543 & 10,243 & $0,001^{* * *}$ & 5,692 \\
\hline MTB i,t-1 & 0,001 & 0,002 & 0,388 & 0,533 & 1,001 \\
\hline PAYOUT i,t-1 & 0,038 & 0,028 & 1,818 & 0,178 & 1,039 \\
\hline$\triangle \mathrm{ALA} i, \mathrm{t}-1$ & $-0,296$ & 0,181 & 2,677 & 0,102 & 0,744 \\
\hline Const & $-2,221$ & 0,074 & 912,741 & $0,000^{* * *}$ & 0,108 \\
\hline $\begin{array}{l}-2 \text { Log } \\
\text { Likelihood } \\
\text { Maior VIF }\end{array}$ & $\begin{array}{r}1.403,186 \\
2,704\end{array}$ & Cox-Snell R2 & 0,012 & Nagelkerke R2 & 0,025 \\
\hline
\end{tabular}

O resultado positivo do coeficiente da variável FCL/AT significa que a probabilidade de ocorrera recompra de ações é maior para as empresas que possuem fluxo de caixa positivo no ano anterior à recompra. Isso confirma a teoria do fluxo de caixa livre, a qual explica que, quanto maior o fluxo de caixa livre da empresa, maior é a chance de a empresa recomprar ações, pois as recompras de ações permitem que a empresa distribua o excesso de fluxo de caixa, eliminando, assim, o incentivo para o desperdício de investimento, aumentando o valor da empresa (Nohel \&Tarhan, 1998). Estatisticamente falando, o valor do coeficiente ( $\beta$ ) indica que, se a variável FCL/AT aumentar uma unidade, o logaritmo da razão de chance aumentaria em torno de 1,739 unidade.

A hipótese de sinalização de subavaliação das ações é estudada por meio da variável MTB, porém a mesma não se mostrou significativa para a ocorrência da recompra de ações. De acordo com a teoria, o ajuste da estrutura de capital das empresas por meio da alavancagem é um dos motivos para a recompra de ações. Porém, para as empresas que compõem a BM\&FBovespa isso não se aplica,uma vez que o nível de significância estatística ultrapassou o percentual de $10 \%$.

De forma geral, os resultados da Tabela 2 evidenciam que, dos quatro motivos apresentados na literatura, apenas um explica a recompra de ações, conforme outros estudos apresentados neste trabalho. 
A falta de significância da variável PAYOUT, que representa a distribuição de dividendos, já era esperada, uma vez que, no Brasil, as empresas não possuem qualquer incentivo para recomprar ações, pois o percentual de Imposto de Renda que incide sobre o ganho de capital é maior do que nos dividendos.

\subsection{ESTIMAÇÃO DO MODELO LOGIT PARA AS EMPRESAS LISTADAS NA NYSE}

Em relação a estimação do modelo para as empresas listadas na BM\&FBovespa, das 51.001 observações, apenas 22.370 incluíram-se no modelo, em virtude da falta de dados para análise de todos os casos. Destas 22.370 observações incluídas, 10.866 se referem às empresas que recompraram ações e 11.504 se referem às empresas que não recompraram ações.

Os resultados do teste VIF apontam que não há qualquer correlação significante entre as variáveis, pois todos os valores apresentados estão abaixo de 10, sendo o maior deles 1,054.

Na Tabela 3 apresentam-se os resultados da estimação do modelo Logit para o grupo das empresas listadas na NYSE. De acordo com essas informações, quatro variáveis explicam a recompra de ações efetuada por essas empresas.

\begin{tabular}{|c|c|c|c|c|c|}
\hline Variáveis & $\beta$ & Erro-padrão & Wald & Sig & $\operatorname{Exp}(\beta)$ \\
\hline FCL/AT i,t-1 & 3,048 & 0,120 & 649,103 & $0,000 * * *$ & 21,081 \\
\hline MTB i,t-1 & 0,000 & 0,000 & 1,204 & 0,272 & 1,000 \\
\hline PAYOUT i,t-1 & $-0,003$ & 0,002 & 2,910 & $0,088^{*}$ & 0,997 \\
\hline$\triangle \mathrm{ALA} i, \mathrm{t}-1$ & $-0,020$ & 0,015 & 1,864 & 0,172 & 0,980 \\
\hline Const & $-0,002$ & 0,014 & 0,027 & 0,869 & 0,998 \\
\hline $\begin{array}{l}-2 \text { Log } \\
\text { Likelihood } \\
\text { Maior VIF }\end{array}$ & $\begin{array}{r}29.903,139 \\
1,054\end{array}$ & Cox-Snell R2 & 0,048 & Nagelkerke R2 & 0,063 \\
\hline
\end{tabular}

A variável FCL/AT foi a que apresentou maior coeficiente, significando que o logaritmo da razão de chance de ocorrer a recompra varia em 3,048, quando aumentada uma unidade nessa variável. É importante observar que, além de um coeficiente alto, o p-valor dessa variável é significante a 1\%, como se pode observar na coluna Sig, o que reforça a influência dessa variável na recompra de ações.

Conforme Dittmar (2000) argumenta, a variável PAYOUT apresenta coeficiente negativo, o que significa que, quanto maior for essa variável, menor é possibilidade da recompra de ações acontecer. Quanto maior o pagamento de dividendos no ano anterior, menor é a probabilidade da recompra de ações acontecer, isso porque as recompras de ações podem substituir os dividendos,em virtude da vantagem fiscal que possuem. Os resultados do estudo de Dittmar (2000), realizado com empresas durante o período de 1977 a 1996, foram estatisticamente insignificantes, ou seja, os testes apontam que a recompra de ações não é um substituto para os dividendos.

A variável $\triangle A L A$ não foi significativa, demonstrando que, estatisticamente, não tem como se confirmar essa relação. Diferentemente desse resultado, Nohel e Tarhan (1998) constataram que a alavancagem é um dos motivos para o aumento das recompras de ações no ano seguinte, ou seja, a recompra de ações é explicada pela sua alavancagem no ano anterior à recompra. Ressalta-se que esses autores trabalharam com uma amostra de empresas que anunciaram recompra de ações no período de 1978 a 1991 de empresas listadas nas bolsas NYSE, AMEX e NASDAQ. 


\subsection{COMPARAÇÃO DOS RESULTADOS DAS ESTIMAÇÕES PARA AS EMPRESAS DA BM\&FBOVESPA E DA NYSE PARA EXPLICAÇÃO DOS MOTIVOS DE RECOMPRA DE AÇÕES}

Uma vez já estimados e interpretados os resultados da estimação para a amostra da BM\&FBovespa e da NYSE, parte-se para a comparação e indagações sobre tais resultados, a fim de verificar as semeIhanças e/ou divergências encontradas em ambos os modelos. No Quadro 1 são apresentados os sinais esperados e encontrados para cada variável em cada uma das estimações, apenas para as variáveis que foram significativas a 1,5 e 10\% em ambos.

Tabela 4: Sinais esperados e encontrados nas estimações para as empresasda BM\&FBovespa e da NYSE, no período de 2000 a 2014

\begin{tabular}{ccccc}
\hline \multirow{2}{*}{ Variáveis } & \multicolumn{2}{c}{ Modelo BM\&FBovespa } & \multicolumn{2}{c}{ Modelo NYSE } \\
\cline { 2 - 4 } & Esperado & Encontrado & Esperado & Encontrado \\
\hline FCL/ATi,t-1 & $(+)$ & $(+)^{* * *}$ & $(+)$ & $(+)^{* * *}$ \\
\hline MTBi,t-1 & $(-)$ & $(+)$ & $(-)$ & $(+)$ \\
\hline PAYOUTi,t-1 & Nenhum & $(+)$ & $(-)$ & $(-)^{*}$ \\
\hline AALAi,t-1 & $(-)$ & $(-)$ & $(-)$ & $(-)$ \\
\hline Nota: sinais esperados confirmados: * significante a 10\%; ** significante a 5\%; *** significante a 1\%. \\
Fonte: dados da pesquisa.
\end{tabular}

Observa-se também que, para a estimação das empresas da BM\&FBovespa, apenas uma variável foi significativa e apresentou o sinal de acordo com o que foi esperado, a saber: FCL/AT. Além disso, para a variável PAYOUT no modelo composto pelas empresas listadas na BM\&FBovespa, não era esperada qualquer significância e sinal, uma vez que não há relação estabelecida entre a distribuição de dividendos e a recompra de ações. Portanto, o resultado confirmou as expectativas, uma vez que não há qualquer incentivo para essas empresas recomprarem ações em detrimento da distribuição de dividendos, como consta na literatura.

Quando se observam os sinais do modelo NYSE, verifica-se que as variáveis FCL/AT e PAYOUT foram significativas e confirmaram o sinal esperado da estimação NYSE.

Para o mercado da BM\&FBovespa, o motivo determinante para a recompra de ações foi a existência do fluxo de caixa e, considerando a estimação da NYSE, os dois motivos determinantes para a recompra de ações foram a existência do fluxo de caixa livre e a distribuição de dividendos..

Tendo em vista esses resultados, pode-se afirmar que, para as duas estimações feitas, a avaliação do fluxo de caixa livre da empresa é relevante para a decisão de recompra de ações, e isso é corroborado pela literatura, a qual explica que, quanto maior o FCL da empresa, maior são as chances de a firma recomprar ações. Isso porque o $\mathrm{FCL}$ gera recursos que os gestores podem utilizar de forma ineficaz, ou seja, gerando VPL negativo, o que não condiz com a necessidade da empresa e dos acionistas, gerando conflito de agência (Boudry et al., 2013). Por isso, quando detectado FCL, a empresa recompra ações, como forma de diminuir esse excesso e consequente diminuição do conflito de agência. Percebe-se, então, que há semelhanças e diferenças entre os motivos pelos quais as empresas recompram ações, isso significa que o nível de desenvolvimento no qual se encontra cada mercado, podem influenciar esses resultados.

\section{CONSIDERAÇÕES FINAIS}

O objetivo geral desta pesquisa foi analisar quais são os motivos determinantes para recompra de ações efetuadas por empresas listadas na BM\&FBovespa e na NYSE. Os motivos analisados foram: (a) 
fluxo de caixa livre; (b) sinalização de que as ações estão subavaliadas; (c) distribuição de dividendos; e (d) interesse das empresas em ajustar a estrutura de capital por meio da alavancagem.

Percebeu-se que a diferença, em quantidade de empresas que realizam operações de recompras de ações na BM\&FBovespa e na NYSE é significativa, pois nos anos de 2000 a 2014, 12.224 empresas participantes da NYSE recompraram ações,enquanto que apenas 214 participantes da BM\&FBovespa realizaram esse tipo de operação. Essa divergência pode ser em virtude de haver concentração acionária no Brasil, pois como as ações das empresas estão concentradas nas mãos de poucos investidores, para estes não seria interessante que a empresa recomprasse ações, uma vez que já possuem a maior quantidade das ações do mercado.

Os resultados da primeira estimação, composto pelas empresas não financeiras listadas na BM\&FBovespa apontam que o fluxo de caixa livre explica a recompra de ações efetuada pelas empresas. Além disso, como era esperado, para as empresas listadas na BM\&FBovepa, não se verificou qualquer influência da distribuição de dividendos sobre a recompra de ações, isso porque, no Brasil, não há incentivo para uma diminuição da distribuição de dividendos em detrimento de um aumento na recompra de ações.

Os resultados referentes a estimação que contém as empresas da NYSE também apontam o fluxo de caixa livre como um motivo determinante para a recompra de ações. A diferença é que, além deste, a distribuição de dividendos afeta a recompra de ações. Isso pode ser justificado devido à legislação nos EUA, pois, de acordo com ela, os ganhos de capital pagos em detrimento das ações possuídas pelos acionistas são tributados a taxas menores do que os dividendos, gerando um benefício fiscal, diferentemente do que ocorre no Brasil.

Conclui-se, então, que os motivos que explicam a recompra de ações das empresas da BM\&FBovespa e da NYSE são diferenciados, pois há todo um conjunto de características que afetam esses resultados. O nível de desenvolvimento do mercado no qual as empresas estão inseridas é um exemplo disso, pois é sabido que o mercado norte-americano é mais antigo e ativo do que o mercado brasileiro, e, além disso, as culturas de cada país são diferentes. Nos EUA, grande parte da população investe no mercado mobiliário, enquanto que no Brasil esse tipo de investimento é mínimo, uma vez que a poupança é o principal captador de recursos, pois apresenta um mínimo risco de perda de capital.

Por fim, cabe aqui ressaltar algumas limitações inerentes a esta pesquisa, como, por exemplo: (a) não segregação dos tipos de recompra utilizados, uma vez que a base de dados utilizada não possibilitou a verificação de tal ação; (b) não verificação da influência dos JSCP na recompra de ações; (c) análise apenas das empresas listadas em duas bolsa de valores, a BM\&FBovespa e a NYSE; (d) não disponibilidade de todos os dados para a estimação do modelo; e (e) não balanceamento da quantidade de empresas que recompraram e que não recompraram ações (em virtude da falta de um critério neutro para tal).

REFERÊNCIAS

Arikan, A. M.; \&Capron, L. (2010).Do newly public acquirers benefit or suffer from their pre-IPO affiliations with underwrites and VCs? Strategic Management Journal, 31(12), p. 1257-1289.

Berk, J.; DeMarzo, P. (2010). Finanças empresariais: essencial. Tradução: Christiane de Brito Andrei. Porto Alegre: Bookman.

Bessler, W.; Drobetz, W.; Seim, M.; \& Zimmermann, J. (2015). Equity issues and stock repurchases of initial public offerings. European Financial Management, p. 1-43. Recuperado em 25 de junho, 2014, de http://ssrn.com/abstract=2488526. 
Boudry, W. I.; Kallberg, J. G.;\& Liu, C. H. (2013). Investment opportunities and share repurchases. Journal of Corporate Finance,23, p. 23-38.

CVM - Comissão de Valores Mobiliários (2015). Instrução CVM n 299, de 9 de fevereiro de 1999. Brasília, 2015. Recuperado em 28 de outubro, 2015, de http://www.cvm.gov.br/legislacao/inst/inst299.html.

CVM - Comissão de Valores Mobiliário. (2015). Instrução CVM n 345, de 4 de setembro de 2000. Recuperado em 28 de outubro, 2015, de http://www.cvm.gov.br/legislacao/inst/inst345.html.

Brooks, C. (2008). Introductory econometrics for finance. (2. ed.) Cambridge: Cambridge University Press.

Chan, K.; Ikenberry, D.; \&Lee, I. (2004). Economics sources of gain in stock repurchases. Journal of financial and Quantitative Analysis, v. 39(3), p. 461-479.

Comment, R.; \& Jarrell, G. A. (1991). The relative signaling power of Dutch-auction and fixed price self-tender offers and open-market share repurchases. Journal of Finance, 46, p. 1243-1271.

Corrar, L. J.; Paulo, E.; \&Dias , J. M. Filho. (2007). Análise multivariada: para os cursos de administração, ciências contábeis e economia. São Paulo: Atlas.

Dann, L. Y. (1981). Common stock repurchases: an analysis of returns to bondholders and stockholders. Journal of Financial Economics,9(2), p. 113-138.

Dittmar, A. K. (2000). Why do firms repurchase stock? The Journal of Business, 73(3), p. 331-355.

Durand, D. (1952). Cost of debt and equity funds for business: trends and problems of measurement. Conference on Research on Business Finance, Nova York: National Bureau of Economic Research, p. 215-247.

Eije, H.V.; \& Megginson, W. L. (2008). Dividends and share repurchases in the European Union. Journalof Financial Economics, 89, p. 347-374.

Gabrielli, M. F.; \&Saito, R. (2004). Recompra de ações: regulamentação e proteção dos minoritários. RAE, 44(4), p. 54-67.

Grullon, G.;\& Ikenberry, D. L. (2000). What do we know about stock repurchases? Journal of Applied Corporate Finance, 13(1) p. 31-51.

Grullon, G.;\& Michaely, R. (2002). Dividends, share repurchases, and the substitution hypothesis. Journal of Finance, 57(4), p. 1649-1684.

Grullon, G.; \& Michaely, R. (2004). The information content of share repurchase programs. Journal of Finance,59(2), p. 651-680.

Gujarati, D. N.; \&Porter, D. C. (2011). Econometria básica. (5. ed.) São Paulo: AMGH.

Howe, K. M.; He, J.; \& Kao G. W. (1992). One-time cash flow announcements and free cash-flow theory: share repurchases and special dividends. The Journal of Finance,47(5), p. 1963-1975.

Ikenberry, D.; Lakonishok, J.; \& Vermaelen, T. (2000). Stock repurchases in Canada: performance and strategic trading. Journal of Finance,55(5), p. 2373-2397.

Jagannathan, M.; Stephens, C. P.; \& Weisbach, S. S. (2000). Financial flexibility and the choice between dividends and stock repurchases. Journal of Financial Economics,57(3), p. 355-384.

Jain, B. A.; Shekhar, C.; \&Torbey, V. (2009). Payout initiation by IPO firms: the choice between dividends and share repurchases. The Quarterly Review of Economics and Finance, 49, p. 1275-1297. 
Jensen, M. C. (1986). Agency costs of free cash flow, corporate finance and takeover. American Economic Review,76(2), p. 323-329.

Jiang, Z.; Kim, K. A.; Lie, E.; \&Yang, S. (2013). Share repurchases, catering, and dividend substitution. Journal of Corporate Finance,21, p. 36-50, 2013.

Kayo, E. K.; \& Famá, R. (1997). Teoria da agência e crescimento: evidências empíricas dos efeitos positivos e negativos do endividamento. Caderno dePesquisas em Administração,2(5), p. 1-8.

Lakonishok, J.; \&Vermaelen, T. (1990). Anomalous price behavior around repurchase tender offers. Journal of Finance,45(2), p. 455-477.

Liang, W. L. (2012). Information content of repurchase signals: tangible or intangible information? Journal of Banking \& Finance,36, p. 261-274.

Lie, E. (2005). Operating performance following open market share repurchase announcements. Journal of Accounting and Economics, (39), p. 411-436.

Modigliani, F.; \&Miller, M. H. (1958). The cost of capital, corporation finance and the theory of investment. The American Economic Review,48(3), p. 261-297.

Modigliani, F.; \&Miller, M. H. (1963). Corporate income taxes and the cost of capital: a correction. American Economic Review,58(3), p.433-443.

Nascimento, S. F.; Galdi, F. C.; \&Nossa, S. N. (2011). Motivações determinantes para a recompra de ações: um estudo empírico no mercado de ações brasileiro no período de 1995 a 2008. Rev. Adm. Mackenzie - RAM,12(5), p. 98-121.

Nohel, T.; \& Tarhan, V. (1998). Share repurchase and firm performance: new evidence on the agency costs of free cash flow. Journal of Financial Economics, 49, p. 187-222.

Park, Y.; \&Jung, K. (2005). Stock repurchase in Korea: market reactions and operating performance. Review of Pacific Basin Financial Markets and Policies, 8(1), p. 81-112.

Sarquis, W. S.; Silva, P. Y. C.; Voese, S. B.; \&Fonseca, M. W. (2014, agosto).Análise comparativa do desempenho econômico-financeiro do setor de bens de consumo de empresas listadas na BM\&FBovespa e NYSE. Anais do Congresso Anpcont, Rio de Janeiro, RJ, Brasil, 8.

Spence, M. (1973). Job market signaling.The Quartely Journal of Economics, 87(3), p. 355-374.

Stephens, C.P.; \&Weisbach, M. S. (1998). Actual share reacquisitions in open-market repurchase programs. The Journal of Finance, 53(1), p. 313-333.

Vermaelen, T. (1981). Common stock repurchases and market signalling: an empirical study. Journal of Financial Economics,9 (2), p. 139-183.

Wang, L. H.; Lin, C. H.; Fung, H. G.; \&Chen, H. M. (2013). Ananalysis of stock repurchase in Taiwan. International Review of Economics and Finance, 27, p. 497-513. 